Article

\title{
Development and Evaluation of Applicable Optimal Terminal Box Control Algorithms for Energy Management Control Systems
}

\author{
Yoon-Bok Seong ${ }^{1}$ and Young-Hum Cho ${ }^{2, *}$ \\ 1 Senior Research Engineer, Construction \& Energy Business Division, Korea Conformity Laboratories, 199, \\ Gasandigital 1-ro, Geumcheon-gu, Seoul 08503, Korea; nike21@snu.ac.kr \\ 2 School of Architecture, Yeungnam University, 280 Daehak-Ro, Gyeongsan, Gyeongbuk 38541, Korea \\ * Correspondence: yhcho@ynu.ac.kr; Tel./Fax: +82-53-810-3081
}

Academic Editor: Marc A. Rosen

Received: 16 August 2016; Accepted: 25 October 2016; Published: 9 November 2016

\begin{abstract}
Common energy management control systems (EMCS) in building HVAC systems could be made much more energy efficient without sacrificing comfort. Most researchers have focused on implementing optimal control algorithms in Variable Air Volume (VAV) systems with EMC functions. Previous studies have paid little attention to using terminal box EMC functions integrated with main AHU (Air Handling Unit) systems. Terminal boxes with EMCS may cause occupant discomfort and waste excessive energy if they do not have the proper operation control functions. The objective of this study is to evaluate the impact of energy consumption and estimate building energy savings on the optimal minimum air flow of single duct VAV terminal boxes and develop applicable optimal terminal box control algorithms for EMCS. This paper presents a dynamic model of a VAV terminal box with hydronic reheat, develops optimal terminal box control algorithms and applies the developed EMCS algorithms to an actual building. The results of this study show that optimal terminal box control algorithms can stably maintain the set room air temperature and reduce energy consumption for varying heating loads compared to conventional control algorithms.
\end{abstract}

Keywords: VAV terminal box; control algorithms; energy savings; thermal comfort

\section{Introduction}

HVAC systems consume more than $30 \%$ of building energy. Methods of saving building HVAC energy include installation or replacement of the HVAC system and upgrading the energy management control system (EMCS). Even with improved HVAC equipment, a building cannot achieve energy savings if the system has an unsuitable operation control system. Considerable energy savings can be attained by properly operating the HVAC system. A typical EMCS in a building HVAC system could be made much more energy efficient without sacrificing comfort.

Most researchers have focused on implementing optimal control algorithms in VAV systems with EMC functions. Elovitz et al. [1] and Krakow et al. [2] discussed the minimum outside air control method and economizer for VAV systems. Optimal supply air temperature control in VAV systems was suggested by Ke et al. [3]. Zaheer-uddin [4] suggested optimal operating strategies. Engdahl and Johansson [5] investigated the energy savings potential of a controlled supply air temperature of a VAV based system by a comparison with a constant supply air temperature. Wei [6] examined the major factors that impact the supply air temperature reset schedule which minimizes the overall heating energy, cooling energy and fan power consumption. Nassif and Moujaes [7] proposed a new damper control strategy for the outdoor, discharge and recirculation air dampers of the economizer in a VAV system. Taylor et al. [8] discussed the minimum air flow set point of the terminal units. Cho and Liu 
identified the relationship between the supply air temperature and minimum air flow rate [9] and the correlation between the minimum air flow and discharge air temperature that will maintain room thermal comfort using a CFD simulation [10]. Kang et al. [11] determined the relationship between supply temperature, air flow rate and energy by height and presented a terminal unit air flow rate control method considering stratification and IAQ. Kim et al. [12] presented a method for controlling the supply temperature and air flow rate of a terminal unit to control stratification. Taylor et al. [13] conduct an energy study on systems that use the conventional box and dual maximum box control methods. Zhang et al. [14] investigated how the VAV terminal box minimum air flow setting influences system energy use as well as building IAQ. However, previous studies have paid little attention to using terminal box EMC functions that are integrated with the main AHU system.

Terminal boxes are one of the major building HVAC components and directly impact building room comfort and energy costs. The minimum air flow of terminal boxes is a key factor for comfort, indoor air quality (IAQ) and energy cost. Current terminal boxes with EMCS may cause occupant discomfort and waste energy because they have inappropriate operation control functions of minimum air flow. Existing terminal boxes in EMC algorithms use mostly empirical methods by using a fixed minimum air flow. This control sequence can cause occupant discomfort or use excessive energy. In addition, advanced optimization and control techniques are too complex between maximum and minimum air flow set point and hard to implement on existing commercially EMCS. Therefore, the optimized control strategy and operation schedules of the terminal boxes with proper minimum air flow should be studied to improve indoor air quality, thermal comfort and energy savings.

The objective of this study is to evaluate the impact of energy consumption and estimate building energy savings on the optimal minimum air flow of single duct VAV terminal boxes and develop applicable optimal terminal box control algorithms for EMCS. This paper presents a dynamic model of a VAV terminal box with hydronic reheat, develops optimal terminal box control algorithms and evaluates the developed EMCS algorithms to an actual building. The terminal box energy consumption and thermal comfort are compared between conventional and improved control using measured data.

\section{VAV Terminal Box Modeling}

The single-duct pressure independent VAV terminal box with hydronic reheat system consists of a modulation damper and temperature sensor and a reheat coil installed in the discharge for spaces requiring heating. Figure 1 presents the schematic diagram of the single-duct pressure independent VAV terminal box with hydronic reheat.

To analysis energy consumption by terminal box, zone load of simple zone sensible load modeling should be calculated as shown in Equation (1); discharge temperature and pressure of reheating coil modeling should be calculated as shown in Equations (2)-(11); and flow rate of damper and valve modeling should be calculated as shown in Equations (12)-(16).

\subsection{Zone Model}

Using the energy balance principle by neglecting the heat gains from the ducts, a simple zone sensible load diagram is shown in Figure 2. 


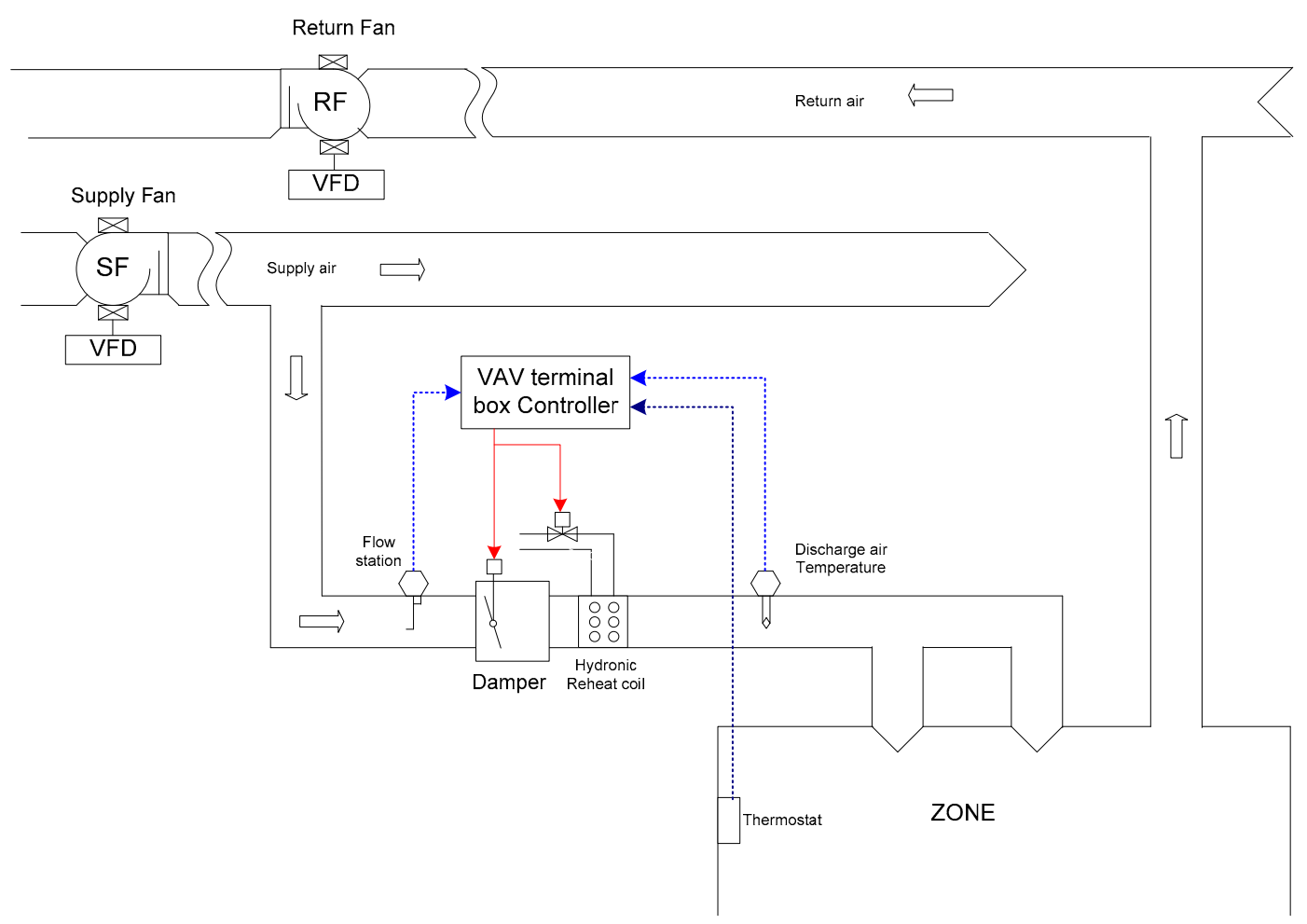

Figure 1. Schematic diagram of a single-duct pressure independent VAV terminal box with hydronic reheat.

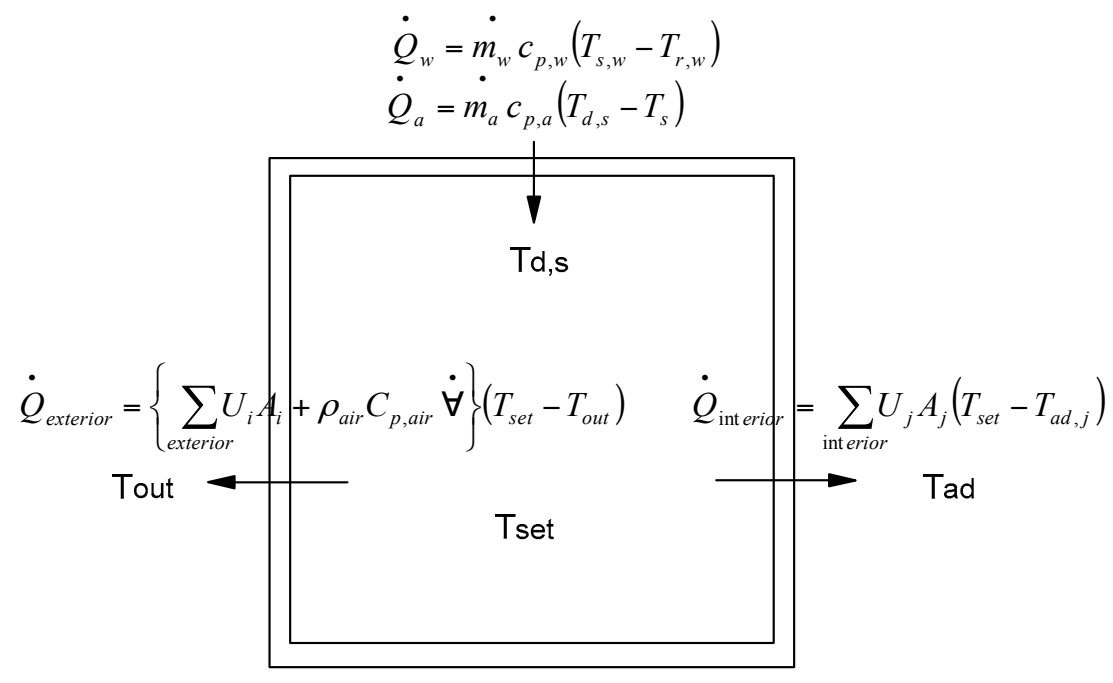

Figure 2. The terms in a zone load calculation.

The fully mixed air mass temperature is given by Equation (1).

$$
\frac{d \cdot T_{R}}{d t}=\frac{1}{\rho \cdot V \cdot C_{a}}\left\{q_{i}+\left(\sum_{\text {exterior }} U_{i} A_{i}+\dot{m}_{v} \cdot C_{a}\right) \cdot\left(T_{r}-T_{\text {out }}\right)+\sum_{\text {interior }} U_{j} A_{j}\left(T_{r}-T_{a d, j}\right)\right\}
$$

\subsection{Reheating Coil Model}

The reheating coil is the most important connection between the AHUs and the zone air distribution system. The reheating coil model uses an approximate equation for effectiveness as 
a function of NTU (number of transfer units) for a typical cross flow heat exchanger with both fluids unmixed type. Total heat transfer rate, water and air side heat flux can be calculated by Equations (2)-(4). When the room can maintain a constant temperature, total heat transfer, the air and water side heat flux have a heat balance as in Equation (5).

$$
\begin{gathered}
\dot{Q}_{\text {total }}=\varepsilon \cdot C_{\min }\left(T_{s, w}-T_{s}\right) \\
\dot{Q}_{w}=C_{w}\left(T_{s, w}-T_{r, w}\right) \\
\dot{Q}_{a}=C_{a}\left(T_{d, s}-T_{s}\right) \\
\dot{Q}_{a}=\dot{Q}_{w}=\dot{Q}_{\text {total }}
\end{gathered}
$$

The steady state air and water outlet temperature are found using the definition of heat exchanger effectiveness by Equations (6) and (7).

$$
\begin{gathered}
T_{d, s}=T_{s}+\varepsilon \cdot \frac{C_{\min }}{C_{a}} \cdot\left(T_{s, w}-T_{s}\right) \\
T_{r, w}=T_{s, w}-\frac{C_{a}}{C_{w}} \cdot\left(T_{d, s}-T_{s}\right)
\end{gathered}
$$

Air and water dynamic outlet temperature are calculated using coil time constant by Equations (8) and (9).

$$
\begin{aligned}
& \frac{d T_{D, d, s}}{d t}=\frac{T_{d, s}-T_{D, d, s}}{t_{c o i l}} \\
& \frac{d T_{D, r, w}}{d t}=\frac{T_{r, w}-T_{D, r, w}}{t_{c o i l}}
\end{aligned}
$$

Air and water inlet pressure are calculated from the outlet pressure and flow rates by Equations (10) and (11).

$$
\begin{gathered}
P_{a, i}=P_{a, o}+k_{a} \cdot m_{a}{ }^{2} \\
P_{w, i}=P_{w, o}+k_{w} \cdot m_{w}{ }^{2}
\end{gathered}
$$

\subsection{Damper and Valve Model}

A damper or valve is essentially a variable fluid resistance. The method in which the flow rate varies with damper or valve position is known as the damper or valve characteristic. The model calculated the inlet pressure as a function of mass flow rate and relative damper or valve position. The pressure loss coefficient for steady-state is derived as Equations (12) and (13). These equations can be related to volume flow rate entering the terminal box as in the following Equations (14) and (15). The flow rate related to air flow resistance can be calculated by Equation (16).

$$
\begin{gathered}
\Delta P_{b o x}=k_{b o x} \cdot P_{v} \\
\Delta P_{b o x}=k_{b o x} \cdot \frac{\rho \cdot v^{2}}{2} \\
\Delta P_{b o x}=k_{b o x} \cdot \frac{\rho \cdot m_{b}^{2}}{2 \cdot A_{b}{ }^{2}} \\
\Delta P_{b o x}=S_{b o x} \cdot m^{2} \\
\dot{m}=\sqrt{\frac{\Delta P_{b o x}}{S_{b o x}}}
\end{gathered}
$$




\section{Optimal Minimum Air Flow}

\subsection{Minimum Air Flow Based on Heating Load}

The minimum air flow for a heating load is the air flow required by the room design heating load. The minimum air flow needed to satisfy the building heating load requirement can be calculated with Equation (17):

$$
\dot{V}_{\min , h}=\frac{Q_{h}}{\rho \cdot C_{p} \cdot\left(T_{d, s}-T_{r}\right)}
$$

where

$\dot{V}_{\min , h}$-air volumetric flow rate for heating load, $\mathrm{ft}^{3} / \mathrm{min}$

$Q_{h}$-Room heating load, Btu/hr

$T_{r}$-Room air temperature, ${ }^{\circ} \mathrm{F}$

$T_{d, s}$-Discharge air temperature, ${ }^{\circ} \mathrm{F}$

$\rho$-standard air density, $\mathrm{lbm} / \mathrm{ft}^{3}$

$\mathrm{C}_{p}$-specific heat of air, Btu/lbm ${ }^{\circ} \mathrm{F}$

In order to calculate the required air flow for the heating load, the discharge air temperature should first be determined. This temperature can be calculated based on Cho and Liu's [10] determined optimal discharge air temperature. It is used to find the proper room air temperature distribution and minimum rate of energy usage. Figure 3 compares the optimal air flow and air flows using differing fixed discharge air temperatures at various occupied conditions. The required air flow in unoccupied conditions was higher than that in occupied conditions because of a high room heating load requirement. During the high room heating load condition (at the low outside air temperature condition), the discharge air temperature is higher than $90^{\circ} \mathrm{F}$ based on the calculated optimal value. However, the discharge air temperature is lower than $90^{\circ} \mathrm{F}$ during the low room heating load condition. Therefore, the discharge air temperature cannot be fixed at a specific temperature; instead, it varies according to the room heating load and air flow.

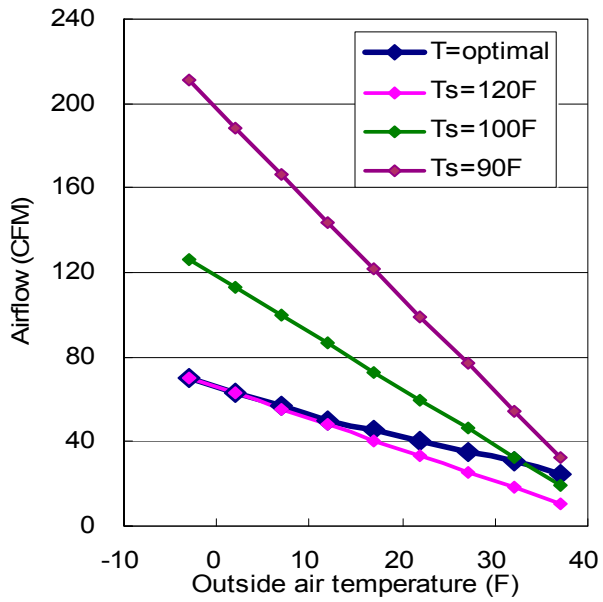

(a)

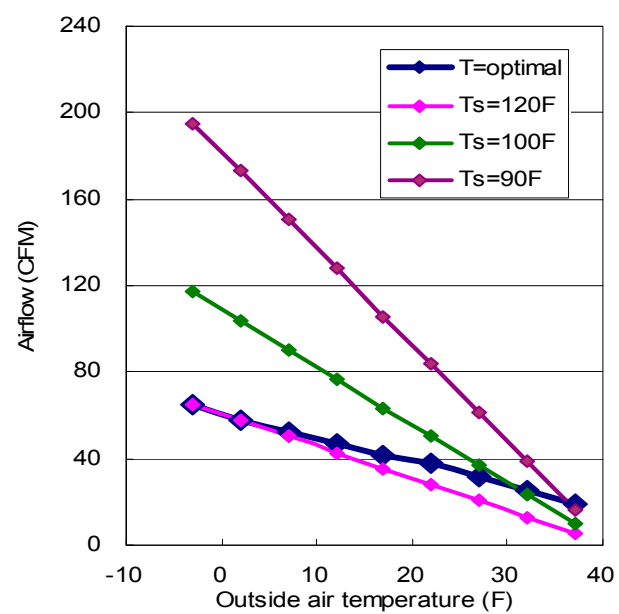

(b)

Figure 3. Cont. 


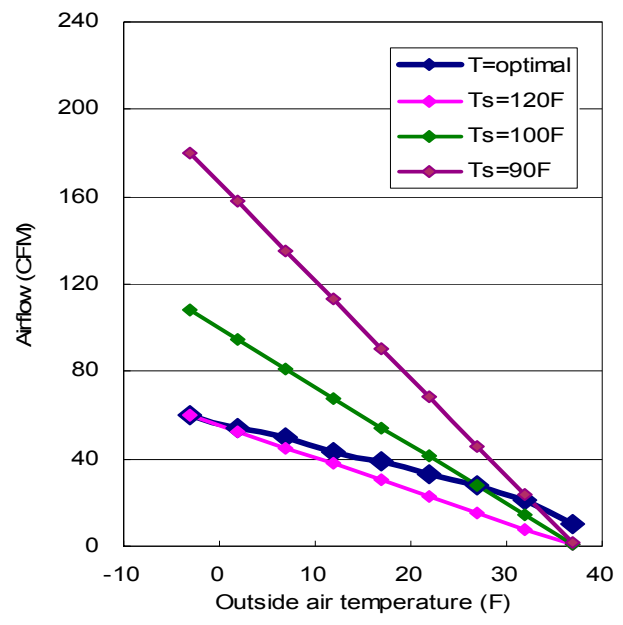

(c)

Figure 3. Comparison of the calculated air flow with different discharge air temperature for different occupied conditions: (a) unoccupied condition; (b) 50\% occupied condition; and (c) fully occupied condition.

Figure 4 compares the reheating energy consumption of the optimal discharge air temperature and the fixed $90^{\circ} \mathrm{F}$ discharge air temperature. The optimal discharge air temperature reduces energy consumption by 33\% to 35\%. During unoccupied conditions, even more reheating energy can be saved.

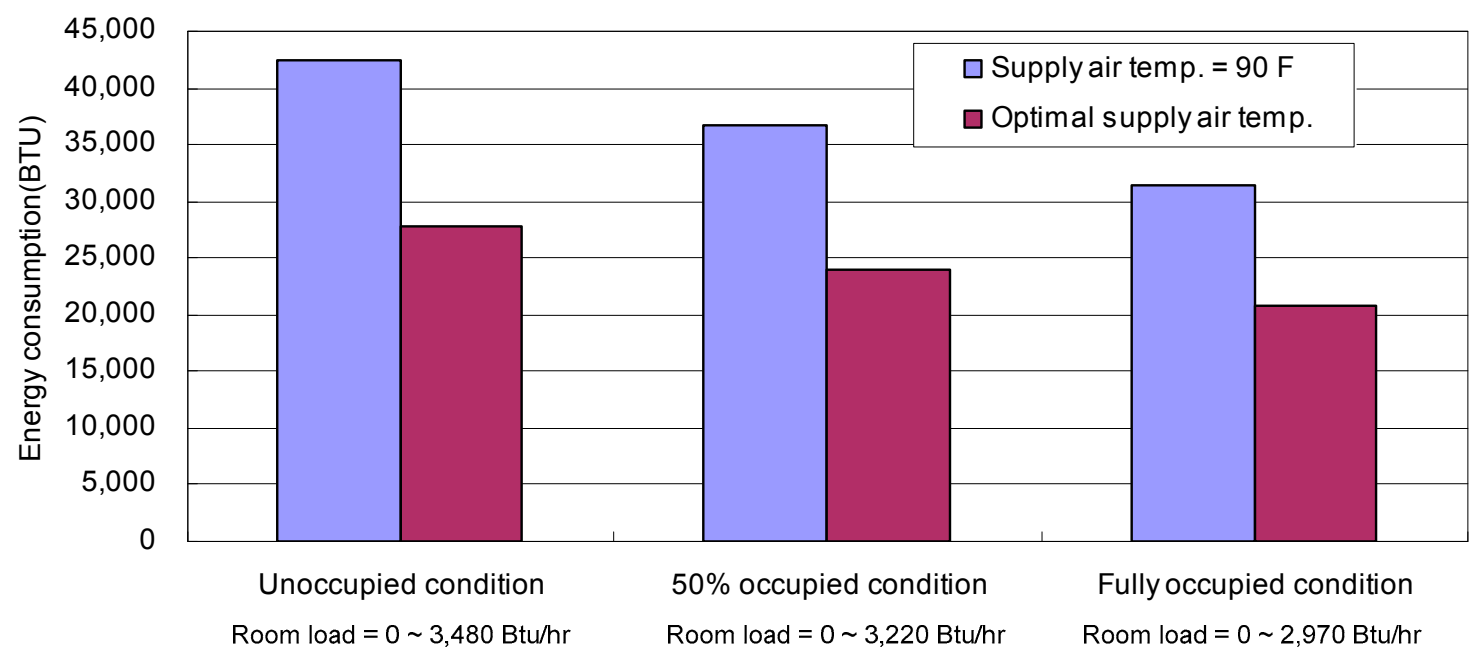

Figure 4. Comparison of the reheating energy consumption between fixed supply air temperature and optimal supply air temperature.

Figure 5 compares the minimum air flow rates of the actual air flow in an existing system with the potentially improved (simulated). These are based on the heating load requirement under differing occupied conditions. The discharge air temperature used the calculated optimal value.

The room heating load was $2970 \mathrm{Btu} / \mathrm{hr}$ at an outside air temperature of $-3^{\circ} \mathrm{F}$ in fully occupied conditions, with a calculated minimum air flow for the room heating load requirement of $60 \mathrm{CFM}$, which is actual minimum air flow in the existing system. The calculated minimum rate of air flow for the room heating load requirement was 0-60 CFM. The minimum air flow ratio for the room heating load requirement was $0 \%-30 \%$ for a design maximum air flow of 200 CFM. Lowering the rate of occupancy increases the required minimum air flow. 


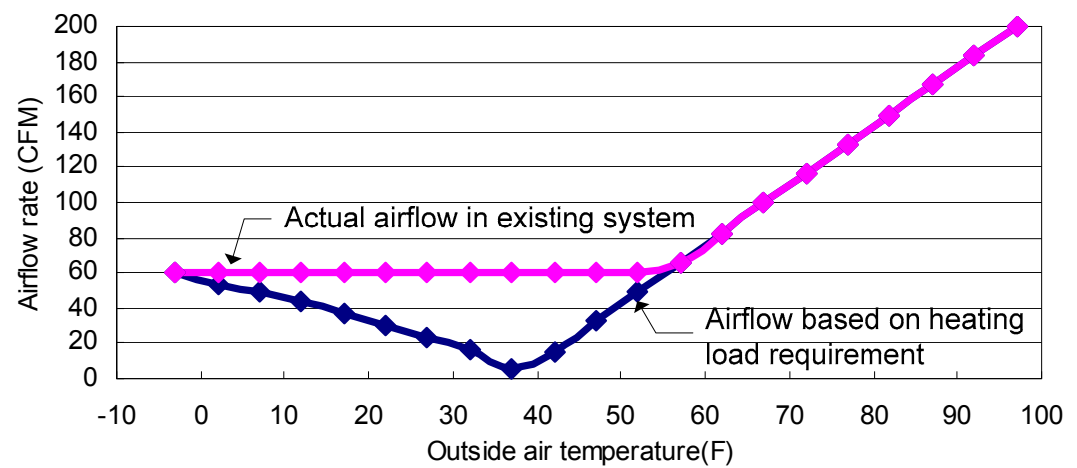

(a)

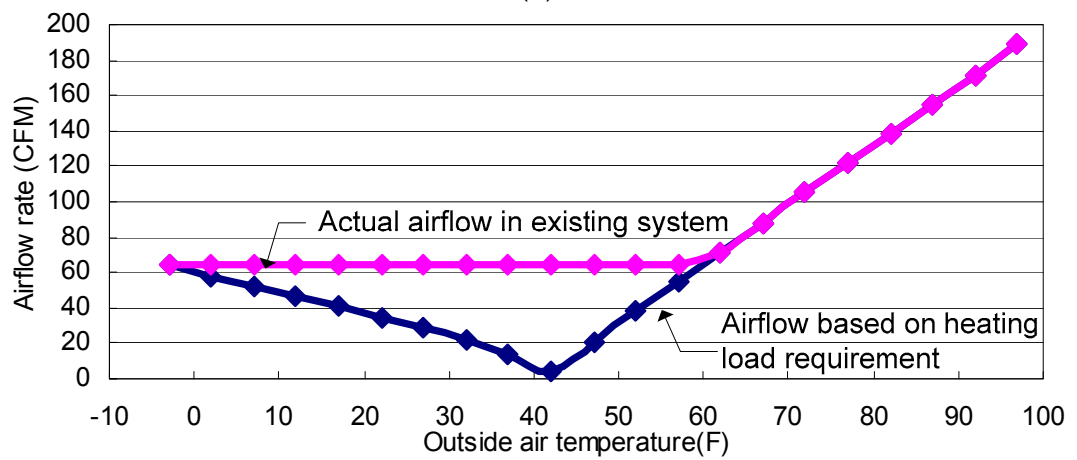

(b)

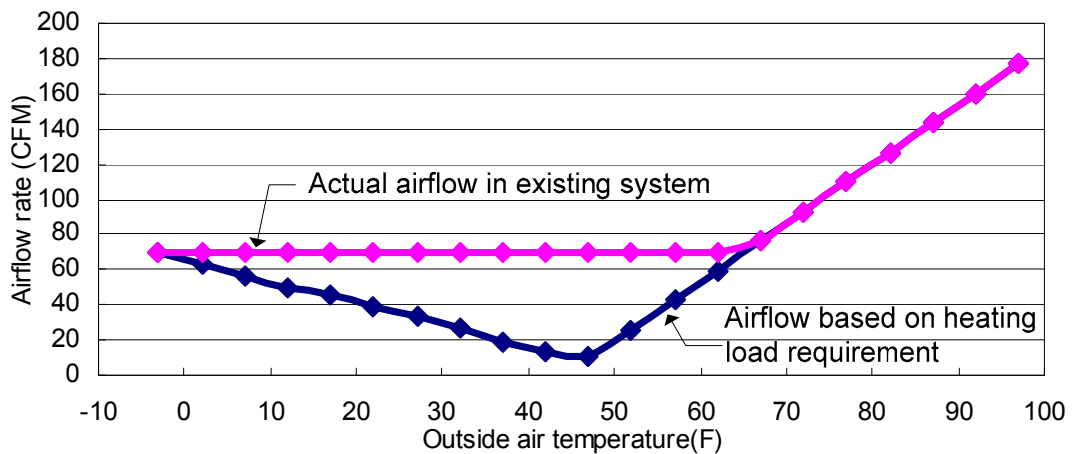

(c)

Figure 5. Comparison of air flow between actual air flow in existing system and calculated air flow based on heating load requirement for different occupied conditions: (a) fully occupied condition; (b) $50 \%$ occupied condition; and (c) unoccupied condition.

\subsection{Minimum Air Flow Based on Ventilation Requirement}

The minimum rate of air flow that satisfies the ventilation requirements can be calculated using Equations (18)-(20).

$$
\alpha_{o a}=\operatorname{Min}\left(\operatorname{Max}\left(\frac{T_{R}-T_{s}}{T_{R}-T_{O A}}, \min o a\right), 1\right)
$$

where

$\alpha_{o a}$-AHU outside air intake ratio, $\%$

$T_{R}$-Return air temperature, ${ }^{\circ} \mathrm{F}$

$T_{O A}$-Outside air temperature, ${ }^{\circ} \mathrm{F}$

$T_{S}$-Supply air temperature, ${ }^{\circ} \mathrm{F}$

$$
\dot{V}_{f}=\left(R_{p} \cdot P_{z}+R_{a} \cdot A_{Z}\right) / E_{z}
$$


where

$\dot{V}_{f}$-air volumetric flow rate for fresh air requirement, $\mathrm{ft}^{3} / \mathrm{min}$

$\dot{V}_{\text {min, }}$-air volumetric flow rate for ventilation, $\mathrm{ft}^{3} / \mathrm{min}$

$R_{p}$-outdoor air flow rate required per person as determined from ASHRAE Standard 62, 2004

$P_{z}$-zone population, person

$R_{a}$-outdoor air flow rate required per unit area as determined from ASHRAE Standard 62, 2004

$A_{z}$-zone floor area, $\mathrm{ft}^{2}$

$$
\dot{V}_{\min , v}=\frac{\dot{V}_{f}}{\alpha_{o a}}
$$

Figure 6 compares the air flow between the actual fresh air flow with different minimum outside air intake ratios and fresh air requirements at different occupied conditions. During the occupied and $10 \%$ minimum outside air intake conditions, the actual fresh air flow was lower than the required minimum air flow. This may cause an IAQ issue.

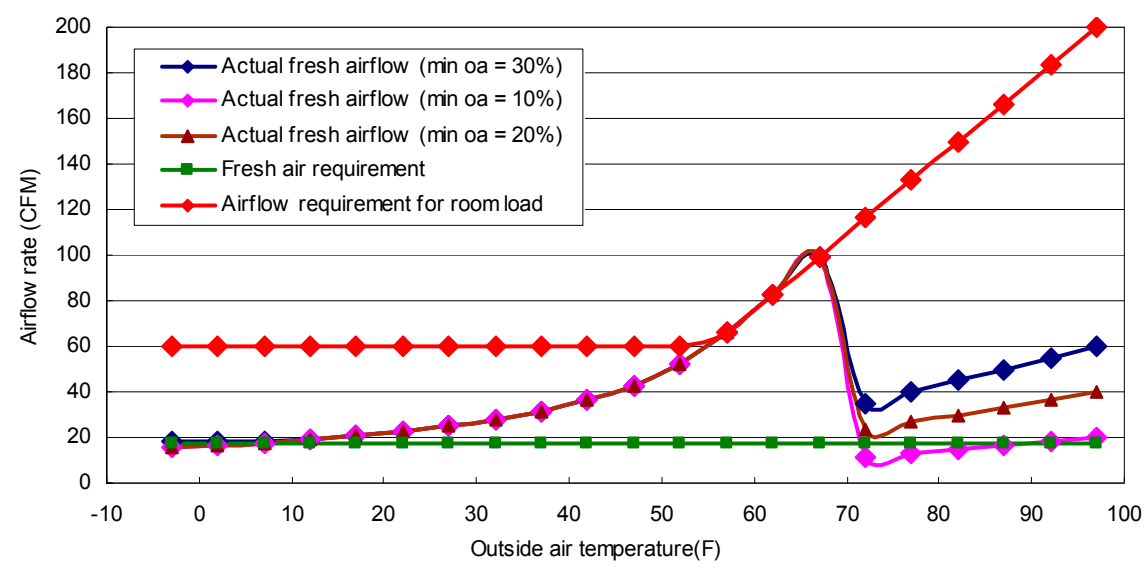

(a)

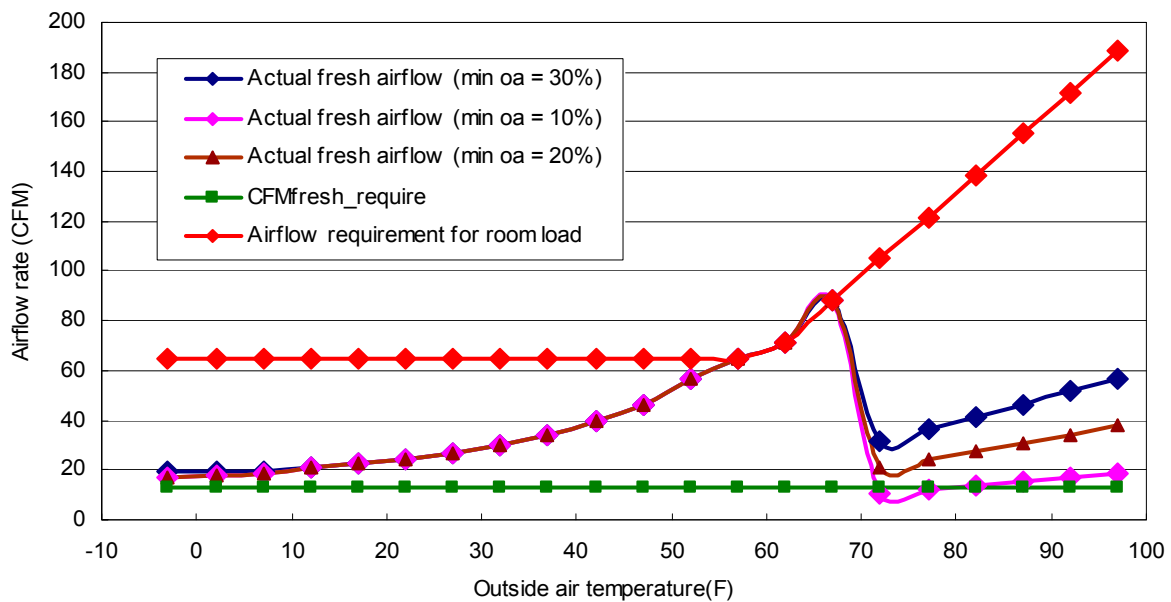

(b)

Figure 6. Cont. 


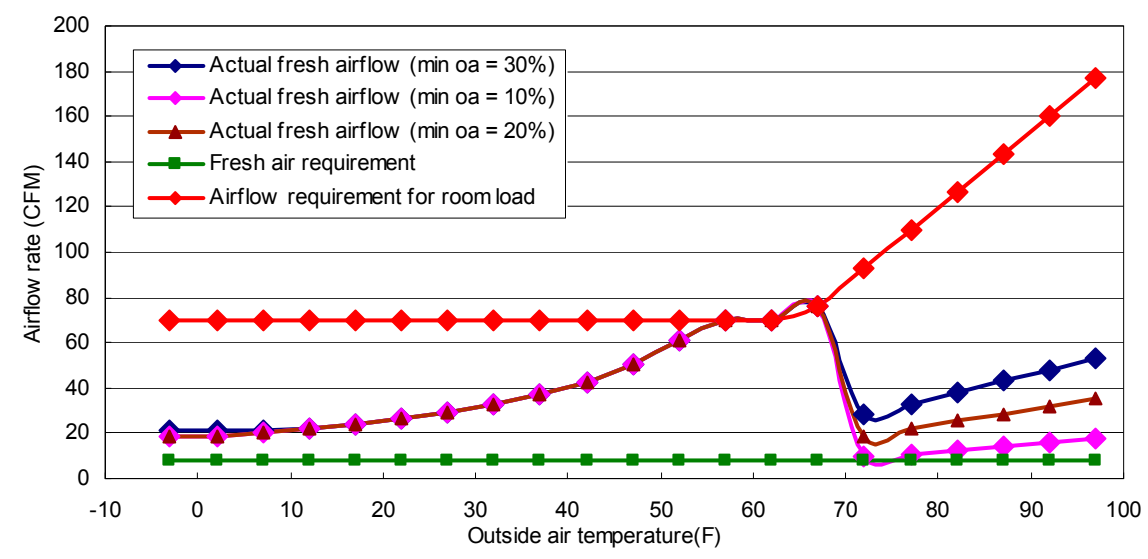

(c)

Figure 6. Comparison of the air flow between actual fresh air flow with different minimum outside air intake ratio and fresh air requirement for different occupied conditions: (a) fully occupied condition; (b) $50 \%$ occupied condition; and (c) unoccupied condition.

Figure 7 shows the calculated minimum air flow based on the fresh air requirement at different occupied conditions. The percentage of outside air in an AHU is in the range of $30 \%-100 \%$ of the full outside air intake according to outside air temperature ranges. The determined minimum air flow for the fresh air requirement was 18-60 CFM, and the minimum air flow ratio for the ventilation requirement was $9 \%-30 \%$ during fully occupied conditions.

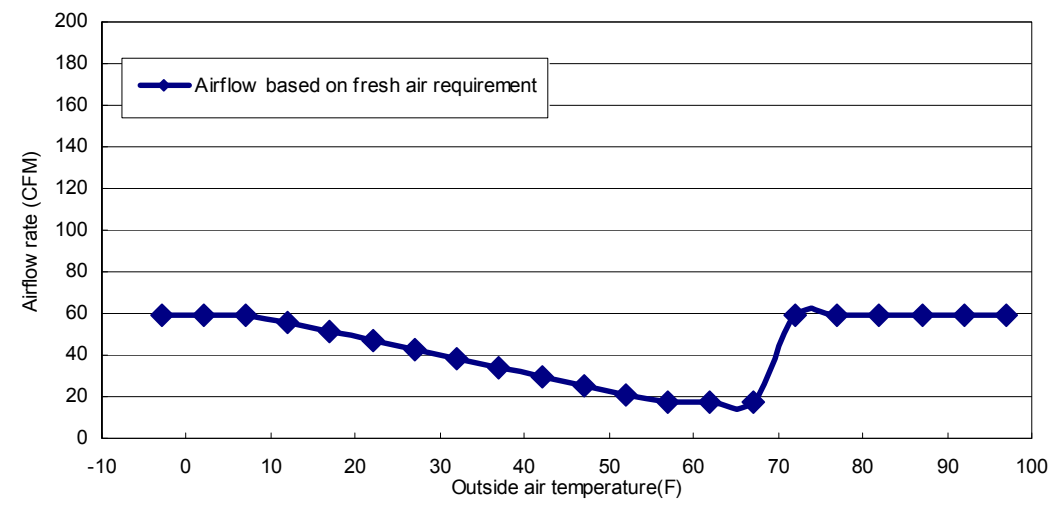

(a)

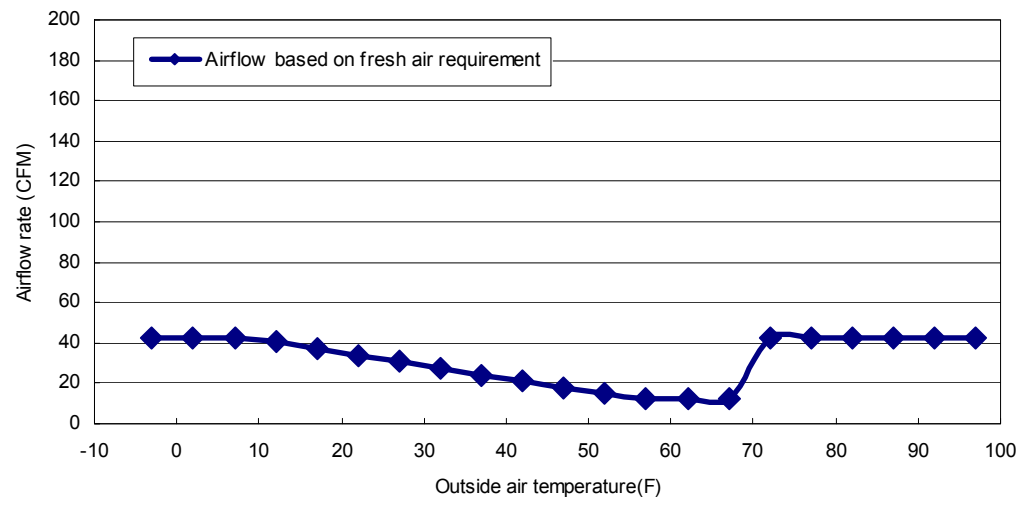

(b)

Figure 7. Calculated minimum air flow based on fresh air requirement for different occupied conditions: (a) fully occupied condition; and (b) 50\% occupied condition. 


\subsection{Minimum Air Flow Requirement}

The minimum air flow set point can be set so that it equals either the highest air flow rate required by the room design heating load or the minimum rate required for ventilation.

$$
\dot{V}_{\min }=\max \left(\dot{V}_{\min , h}, \dot{V}_{\min , v}\right)
$$

Figure 8 shows the calculated minimum air flow for room load and fresh air requirements under differing occupied conditions. During fully occupied conditions, the fresh air requirement served as a more critical factor; however, during unoccupied conditions, minimum air flow can generally be determined by the load requirement.

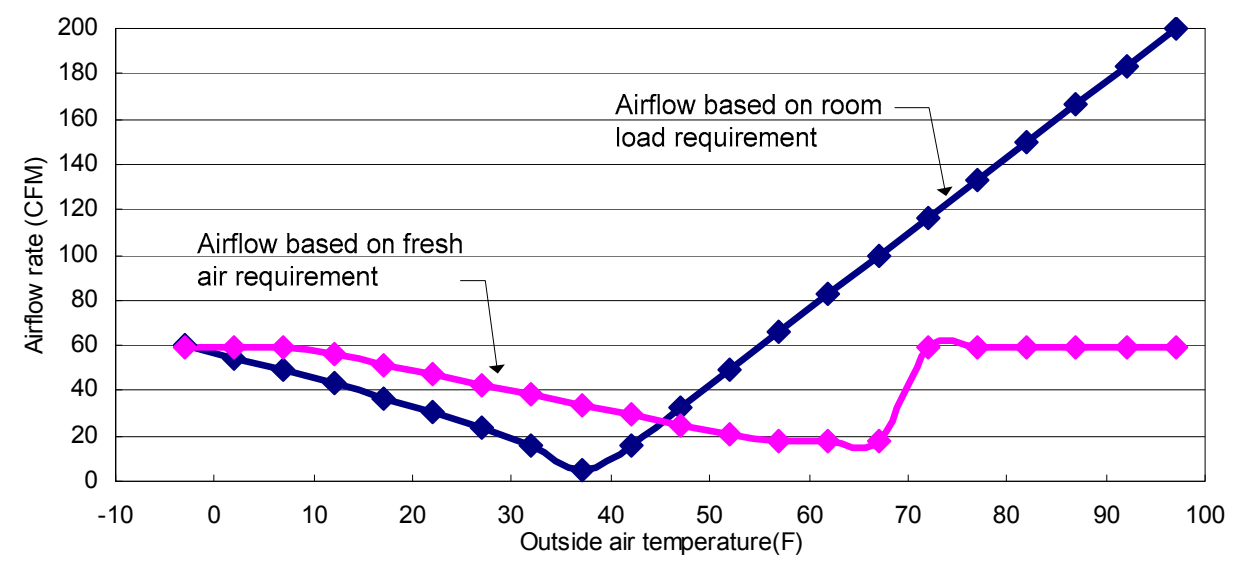

(a)

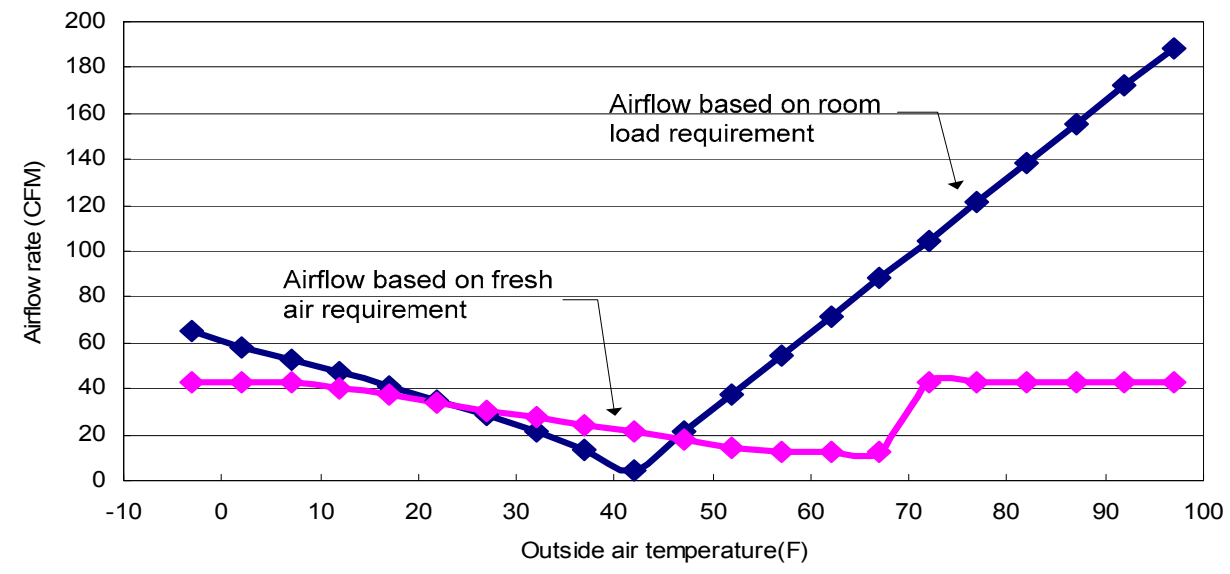

(b)

Figure 8. Determined minimum air flow for room load requirement and fresh air requirement for different occupied conditions: (a) fully occupied condition; and (b) 50\% occupied condition.

Figure 9 compares the existing fixed minimum air flow and the determined air flow, which is selected maximum value between ventilation requirement and heating load requirement, at different occupied conditions. The calculated minimum air flow under unoccupied conditions was lower than in occupied conditions. 


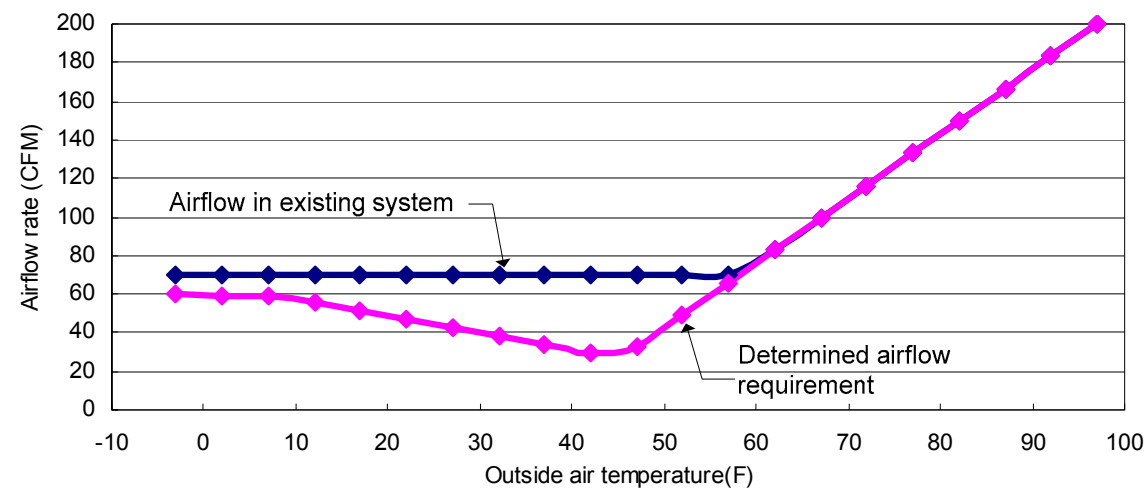

(a)

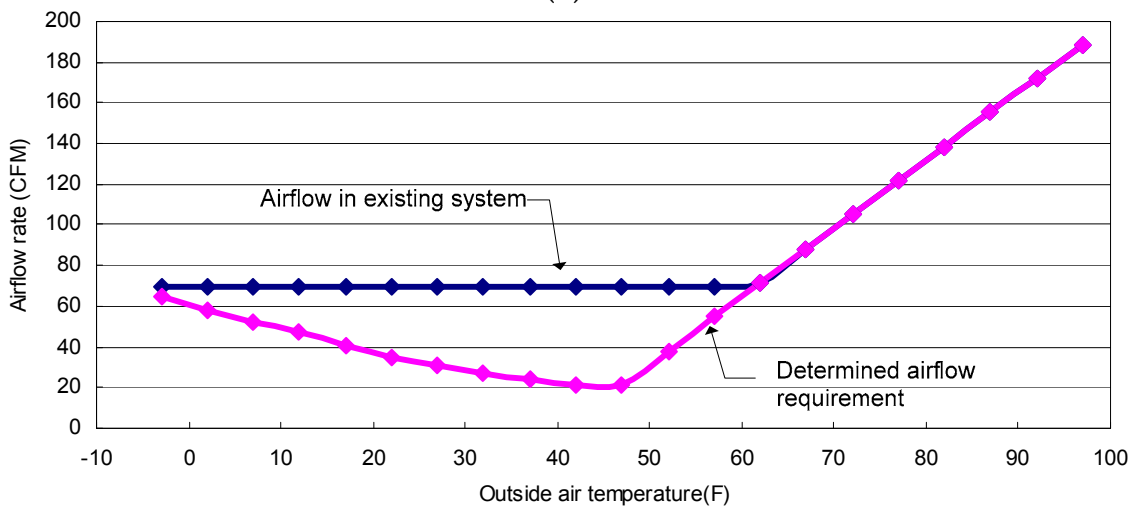

(b)

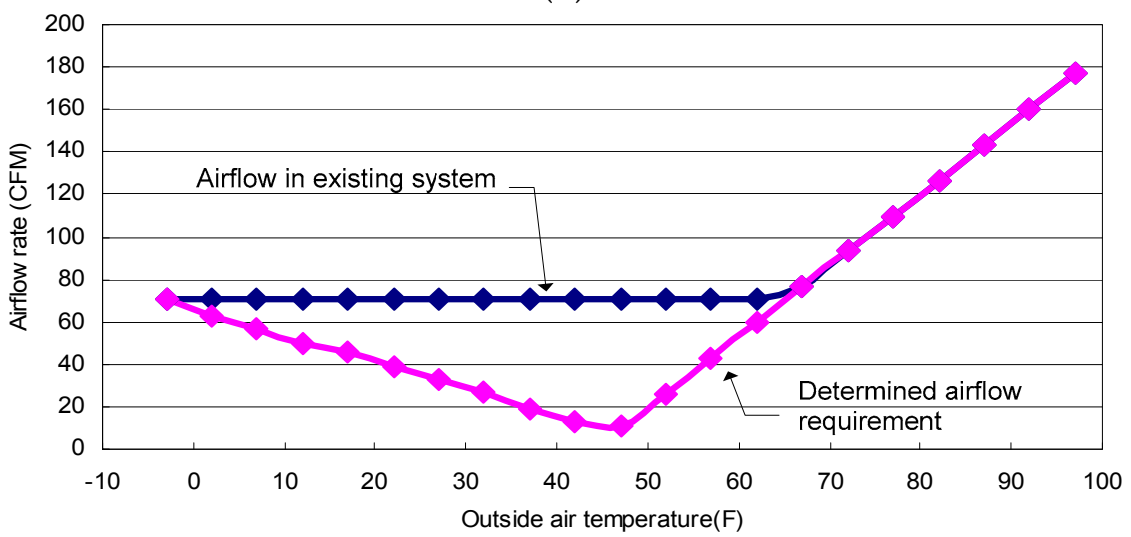

(c)

Figure 9. Comparison of the air flow between existing fixed minimum air flow and the determined air flow for different occupied conditions: (a) fully occupied condition; (b) 50\% occupied condition; and (c) unoccupied condition.

The air flow range with the fixed minimum air flow and optimal air flow in differing occupied conditions. The range of the optimal air flow was $6 \%$ to $35 \%$ of the design air flow. The shaded area between the fixed minimum air flow and optimal air flow represents the potential amount of energy saved. This graph reveals that the energy consumption of the optimal minimum air flow can be less than that of the conventional fixed minimum air flow.

Table 1 displays the calculated minimum air flow and its ratio under differing occupied conditions. The fixed conventional minimum air flow set point was determined in unoccupied conditions. The range of the minimum air flow ratio in unoccupied conditions was greater than in occupied conditions. The graph further indicates that potentially greater energy savings can be expected in unoccupied conditions. 
Table 1. Determined minimum air flow for different occupied conditions and its ratio.

\begin{tabular}{cccccc}
\hline & \multirow{2}{*}{$\begin{array}{c}\text { Design Air Flow } \\
\text { (CFM) }\end{array}$} & \multicolumn{2}{c}{ Minimum Air Flow (CFM) } & \multicolumn{2}{c}{ Minimum Air Flow Ratio (\%) } \\
\cline { 3 - 6 } & & Base Case & Improved Case & Base Case & Improved Case \\
\hline Fully occupied condition & 200 & 70 & $29-70$ & $35 \%$ & $14 \%-35 \%$ \\
$50 \%$ occupied condition & 200 & 70 & $21-70$ & $35 \%$ & $11 \%-35 \%$ \\
Unoccupied condition & 200 & 70 & $11-70$ & $35 \%$ & $6 \%-35 \%$ \\
\hline
\end{tabular}

\section{Optimal Terminal Box Control Algorithms}

Generally, EMCS achieve energy efficiency by improved the scheduling and operation without sacrificing thermal comfort. EMCS functions can be activated based on the time of year, month and the daily operation of building system. In this study, applicable optimal terminal box control algorithms for EMCS functions integrated with AHUs are developed.

\subsection{General Operation Function for an EMCS}

$>$ Objective: To improve thermal comfort and reduce energy consumption

$>$ Definitions:

- Seasonal cycle: summer, winter and spring/fall

- Weekend cycle: the day of the year is a weekend or holiday

- Occupied cycle: the day of the year is a weekday

- Nighttime cycle: the terminal box is disabled

- Start/stop time cycle: before and after working hours

$>$ Process:

The EMCS can automatically classify what season it is currently, depending on the month. There are three seasonal operation modes: summer, winter and spring/fall. For example, if the month of the year is August, the terminal box goes to summer cooling operation mode.

The EMCS considers whether it is a normal cycle or weekend cycle by the day of the year. If the day of the year is a weekend or holiday, the terminal box goes to the "weekend cycle". During the weekend cycle, the terminal box is usually disabled based on the room and outside air conditions. During the week, the system goes to the daily normal operation cycle.

In the daily normal operation cycle, a day is divided into four time periods: nighttime, start time, stop time and "occupied time cycle". During nighttime, the terminal box is disabled independent of the AHU operation. If the room and outside air condition is extremely cold or hot, the terminal box will be enabled during the "nighttime cycle". The decision when the terminal box needs to be enabled from the disabled period is important for energy consumption because most rooms are not continuously occupied. If the occupied time is regular, e.g., an office area, the system can easily figure out the occupied or unoccupied time. Before the occupied operation time, the terminal box goes to the "start time cycle". The system decides the enabled time based on the room conditions needed to pre-cool or warm to attain the desired room set point before the occupied time. During the start/stop cycle, if the room can maintain the room set point, the terminal box is disabled. The system will also need to add special equipment like a motion sensor if the occupied time is too variable. Figure 10 shows the general terminal box operation cycle. 


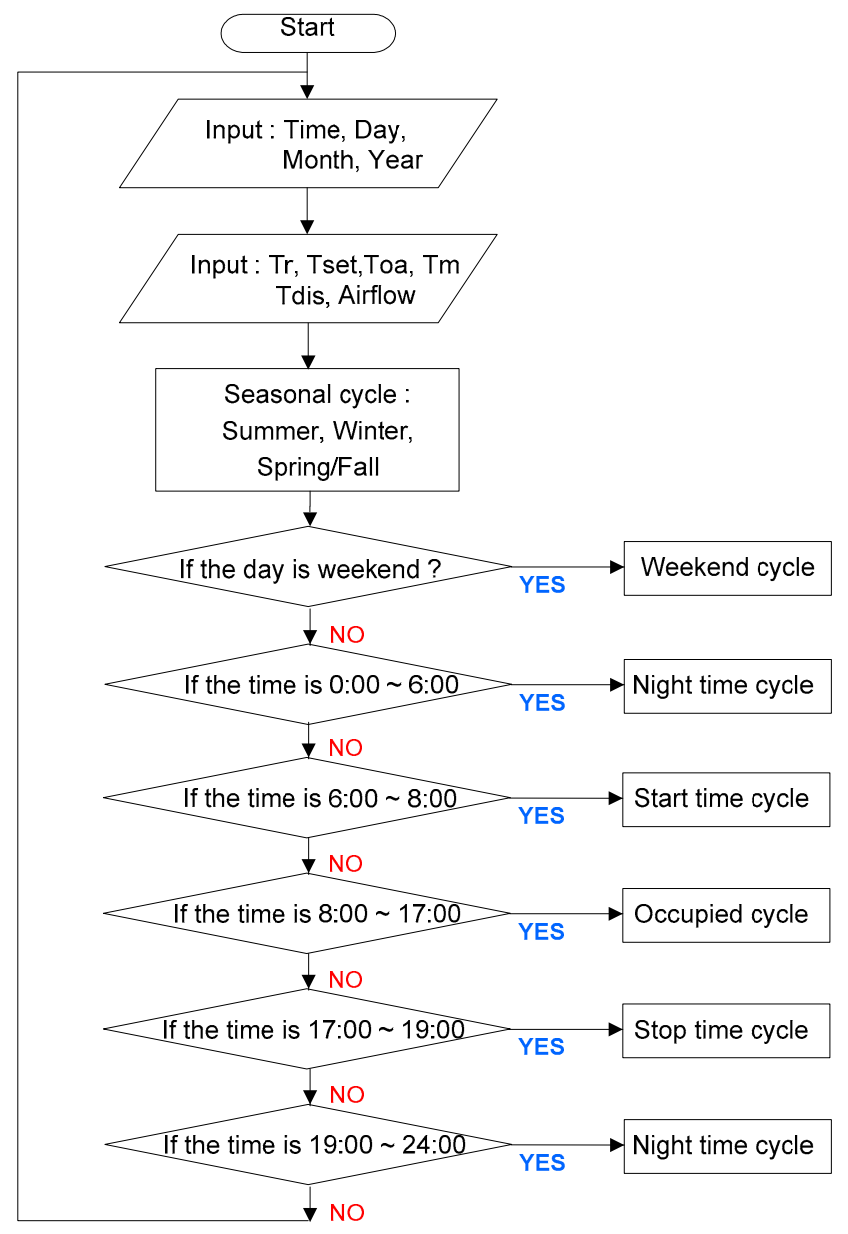

Figure 10. General terminal box operation cycle.

\subsection{Occupied Time Operation for EMCS}

The most complex operation strategy is the occupied time cycle, when the occupants stay in the room. Occupied period control sequences are the most important and require complex EMC functions because of the effect on occupant thermal comfort. Most of all, HVAC control through EMCS should give thermal comfort to occupants. The system can also save energy with an optimal control sequence. The five modes during the occupied time cycle are as follows:

- Ventilation mode: When the room air temperature is equal to its set point deviation (d), the reheat valve is closed; the air flow set point is maintained by the calculated required fresh air intake.

- Cooling mode: When the room air temperature is above its set point deviation (d), the reheat valve is closed; the room temperature set point is maintained by modulating the air flow between the maximum and minimum values.

- Maximum cooling mode: When the room air temperature is above its set point deviation (2d), the reheat valve is closed; the maximum air flow of this mode is higher than that of cooling mode.

- Heating mode: When the room air temperature is below its set point deviation (d), the discharge air temperature is maintained by modulating the reheat valve between its maximum and minimum set point; the air flow set point is the calculated required ventilation air flow.

- Maximum heating mode: When the room air temperature is below its set point deviation (2d), the air flow is maintained between its maximum and minimum values.

Figure 11 shows the control algorithms for operation during the occupied time. 


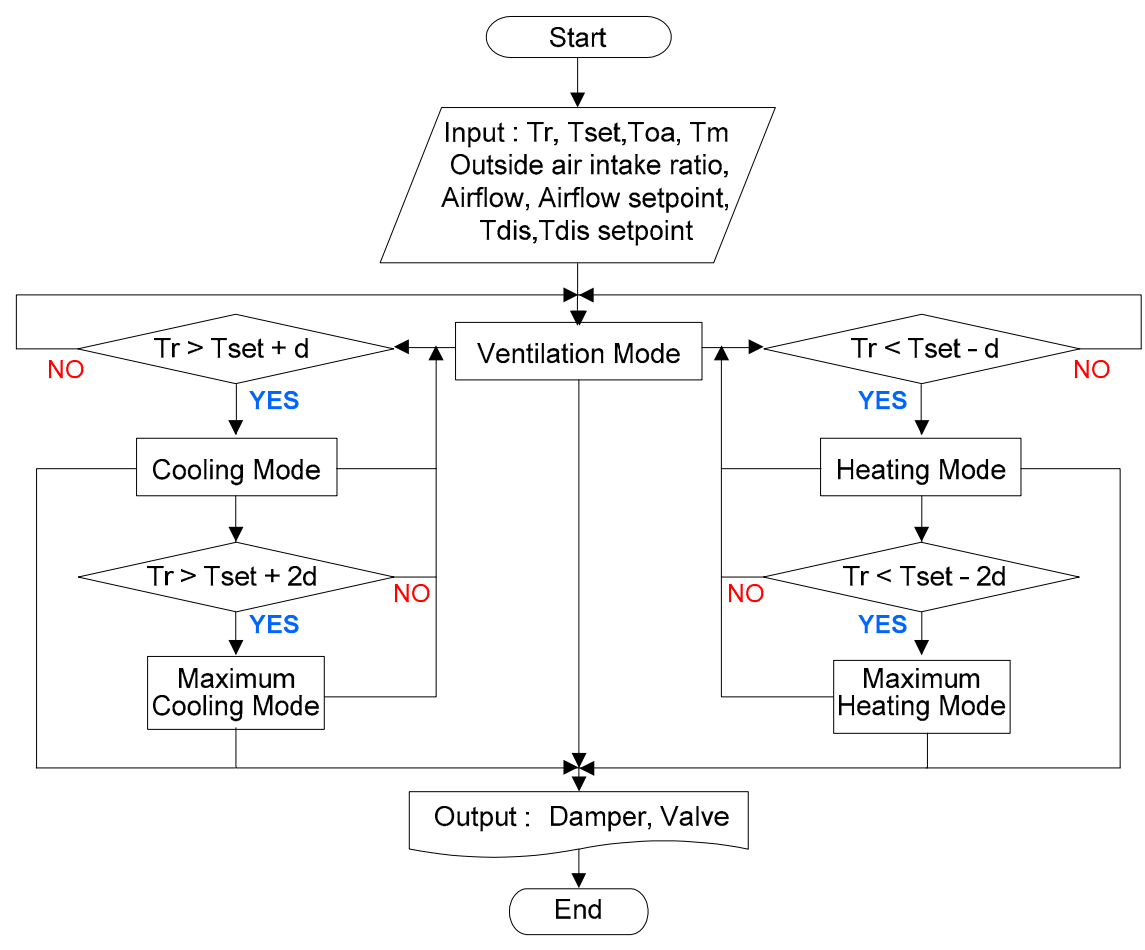

Figure 11. Control algorithms for occupied time operation.

When the terminal box is enabled, the terminal box is set at the ventilation mode. The air flow rate that satisfies the outside air ventilation requirements can be calculated by Equations (18) and (19). The outside air intake ratio can be derived from the AHU's control variable.

Under the ventilation mode, the controller checks two conditions: (1) whether the room temperature is higher than its set point deviation (d); and (2) whether the room temperature is lower than its set point deviation (d).

When the first condition is satisfied, the terminal box is switched to the cooling mode. In the cooling mode, the air flow set point varies between the design cooling air flow and required ventilation air flow to maintain the room temperature. During the cooling mode, the room temperature is higher than its set point deviation (2d), and the terminal box is switched to the maximum cooling mode. Set the maximum cooling air flow to $\alpha$ times the current design cooling air flow set point. If the room temperature is lowered, the terminal box is switched from the maximum cooling to the cooling mode. If the room temperature satisfies within its set point deviation (d), the terminal box is switched from cooling mode to ventilation mode. If the second condition is satisfied, the terminal box is switched from the ventilation mode to the heating mode. The heating air flow is set between the required ventilation air flow and design heating air flow to maintain the room temperature. The discharge air temperature has a maximum set point which cannot be more than $15^{\circ} \mathrm{F}$ above room temperature, as recommended by ASHRAE Standard 62.1-2004 [15]. If the room temperature is lower than its set point deviation (2d), the terminal box is switched to the maximum heating mode. Set the maximum heating air flow to $\alpha$ times the current design heating air flow set point. If the room temperature increases, the terminal box is switched from the maximum heating to the heating mode. If the room temperature is satisfied within its set point deviation (d), the terminal box is switched from the heating mode to ventilation mode. Table 2 shows the control variables for each operation mode. 
Table 2. Summary of operation control variables.

\begin{tabular}{|c|c|c|c|c|c|c|}
\hline & \multirow{2}{*}{ Mode } & \multirow{2}{*}{ Mode Period } & \multicolumn{2}{|c|}{ Air flow Set Point } & \multicolumn{2}{|c|}{ Discharge Temperature Set Point } \\
\hline & & & Maximum & Minimum & Maximum & Minimum \\
\hline \multirow{4}{*}{ Occupied } & Ventilation & Tset $-\mathrm{d}<\operatorname{Tr}<$ Tset $+\mathrm{d}$ & CFM_ventilation & CFM_ventilation & Ts & Ts \\
\hline & Maximum cooling & $\operatorname{Tr}>$ Tset $+2 d$ & $\alpha$ CFM_cooling & CFM_ventilation & Ts & Ts \\
\hline & Heating & $\operatorname{Tr}<$ Tset $-\mathrm{d}$ & CFM_heating & CFM_ventilation & $\operatorname{Tr}+15$ & Ts \\
\hline & Maximum heating & $\operatorname{Tr}<$ Tset $-2 d$ & $\alpha$ CFM_heating & CFM_ventilation & $\operatorname{Tr}+15$ & Ts \\
\hline Unoccupied & Heating & $\mathrm{Tr}<$ Tset $-4 \mathrm{~d}$ & CFM_heating & Zero & $\operatorname{Tr}+15$ & Ts \\
\hline
\end{tabular}

In current practice, a proportional-only controller can result in as fast a response as an offset controller. If the gain is higher, the response of the control system will also increase, but the higher gain also causes overshoot and hunting. To solve this problem, proportional and integral control is the most common and widely used control method in HVAC systems, although it is difficult to select appropriate proportional and integral gains for multiple control loops. Figure 12 shows a schematic diagram for an air flow control loop. To maintain the room air temperature set point, the controller calculates the desired air flow set point. The damper modulates to maintain the air flow set point. Figure 13 shows a schematic diagram for the discharge air temperature control loop. To maintain the room air temperature set point, the controller calculates the desired discharge air temperature set point. The reheating valve modulates to maintain its set point.

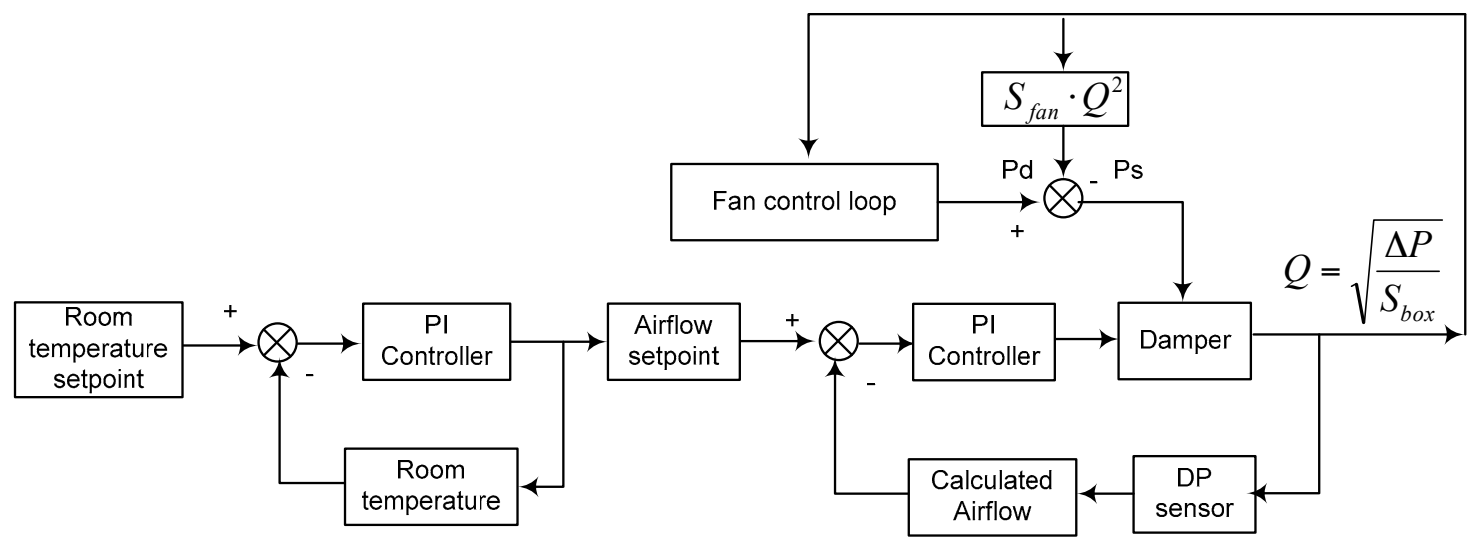

Figure 12. Schematic diagram for air flow control loop.

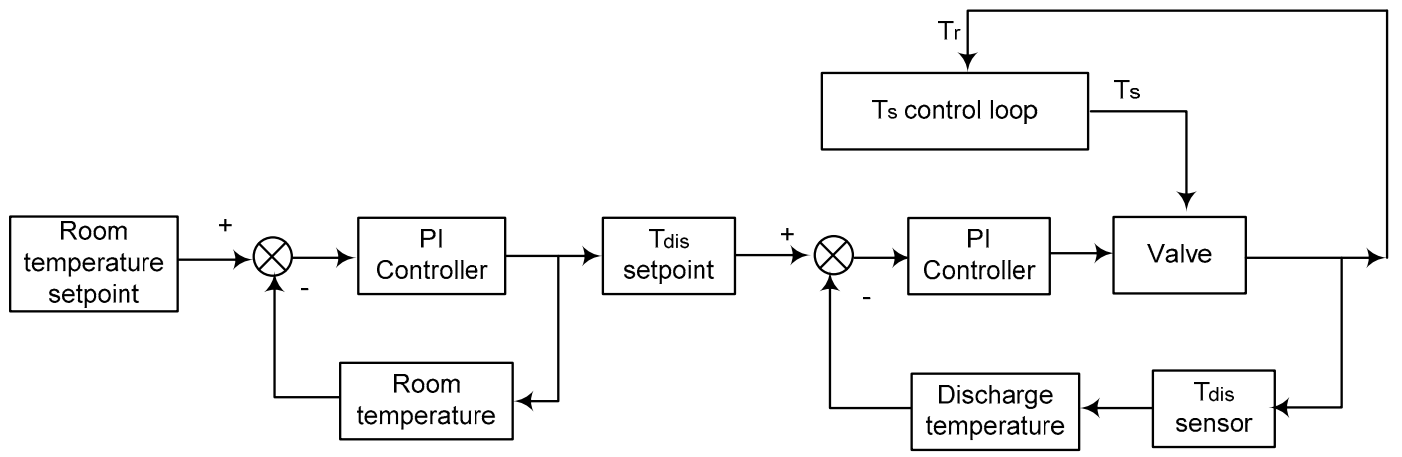

Figure 13. Schematic diagram for discharge air temperature control loop.

\section{Application}

The applied building is a medical center located in Omaha, Nebraska. There are 232 terminal boxes in the building. Most of the terminal boxes are a single-duct pressure independent VAV terminal 
box with hydronic reheat and serve both interior and exterior zones. One typical terminal box, located at the south exterior office room, was chosen in this study to apply the optimal terminal box control sequence. There is normally one person occupying this office; the occupied hours on the weekdays are 8:00 a.m. to 6:00 p.m. The HVAC system operates $24 \mathrm{~h}$ a day, 7 days a week. The room air temperature set point is $73^{\circ} \mathrm{F}$ and the AHU supply air temp set point is $55^{\circ} \mathrm{F}$. The HVAC system EMCS software (Andover, Omaha, NE, USA) is Andover with Plain English ${ }^{\circledR}$ programming. Table 3 shows the applied building system information.

Table 3. Building information.

\begin{tabular}{|c|c|c|}
\hline Item & & Information \\
\hline EMCS Software & \multicolumn{2}{|c|}{ Andover Continuum with Plain English ${ }^{\circledR}$ Programming } \\
\hline \multirow{3}{*}{ Zone } & Location & Omaha, Nebraska \\
\hline & Purpose & Office room \\
\hline & Size & Floor area: $215 \mathrm{ft}^{2}$, Volume: $1550 \mathrm{ft}^{3}$ \\
\hline \multirow{2}{*}{ People } & Number & Normally one Person during occupied hour \\
\hline & Schedule & Occupied hours (8:00 a.m.-6:00 p.m.) \\
\hline \multirow{4}{*}{ Operation condition } & HVAC system & $24 \mathrm{~h}, 7$ days working \\
\hline & AHU supply air temperature & $55 \mathrm{~F}$ \\
\hline & Supply hot water temperature & $140 \mathrm{~F}$ \\
\hline & Room set point & $73 \mathrm{~F}$ \\
\hline \multirow{9}{*}{ EMCS control point } & \multirow{4}{*}{ AHU Input } & Outside air temperature \\
\hline & & Mixed air temperature \\
\hline & & Supply air temperature \\
\hline & & Return air temperature \\
\hline & \multirow{3}{*}{ Terminal box Input } & Space room air temperature \\
\hline & & Discharge air temperature \\
\hline & & Air flow rate \\
\hline & \multirow{2}{*}{ Terminal box Output } & Damper position \\
\hline & & Reheating valve position \\
\hline Terminal box information & Type & $\begin{array}{l}\text { Single-duct pressure independent terminal } \\
\text { box with hydronic reheat coil }\end{array}$ \\
\hline
\end{tabular}

\subsection{Conventional Terminal Box Control}

The type of terminal box in this building is a single-duct pressure independent VAV terminal box with hydronic reheat coil. The existing control sequence is the following. On a call for cooling, air flow will increase as the damper opens towards the fixed maximum air flow set point (250 CFM) to satisfy room air temperature set point. On a call for less cooling, air flow will decrease as the damper closes towards the fixed minimum air flow set point to satisfy the room air temperature set point. With a further call for heat, air flow drops to the minimum air flow set point and the reheat coil valve is modulated to maintain the room air temperature heating set point. The fixed minimum air flow set point (125 CFM) is based on the design heating load air flow. The terminal box operates $24 / 7$ to maintain the room air temperature set point. Figure 14 shows the conventional terminal box control sequence.

To analyze the room air temperature control in an actual system, the room conditions were measured. The range of the room air temperature was $71.5^{\circ} \mathrm{F}-74.6^{\circ} \mathrm{F}$, the discharge air temperature was $55.4^{\circ} \mathrm{F}-134.6^{\circ} \mathrm{F}$, and the supply air flow was $132-248 \mathrm{CFM}$ as shown in Figures 15 and 16 . With a conventional control sequence, the room air temperature is not able to maintain the set point $\left(73^{\circ} \mathrm{F}\right)$ within control deviation. There are two reasons that the room air temperature cannot stably maintain the set room air temperature. One reason is the high minimum air flow set point, while another is the high discharge air temperature. It often causes significant simultaneous heating and cooling and excessive fan power in mild weather. Although a high minimum air flow set point causes excess energy consumption, it produces a large amount of fresh air flow to occupants during operations 
as shown in Figure 16. Therefore, the terminal boxes need to optimize the control sequence according to building operation conditions.

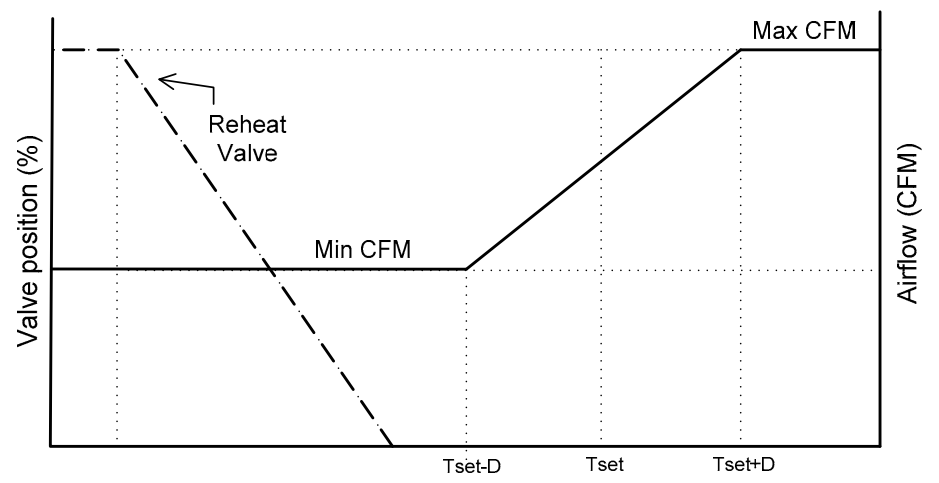

Figure 14. Conventional terminal box control sequence.

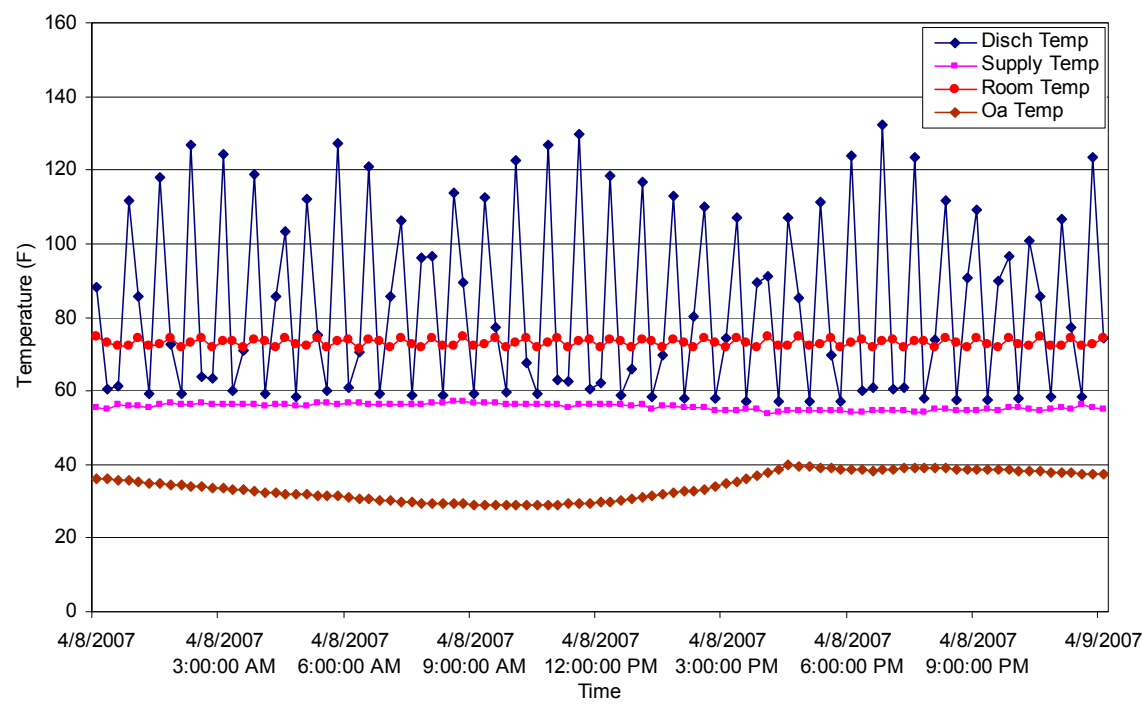

Figure 15. Temperature trending data for conventional control.

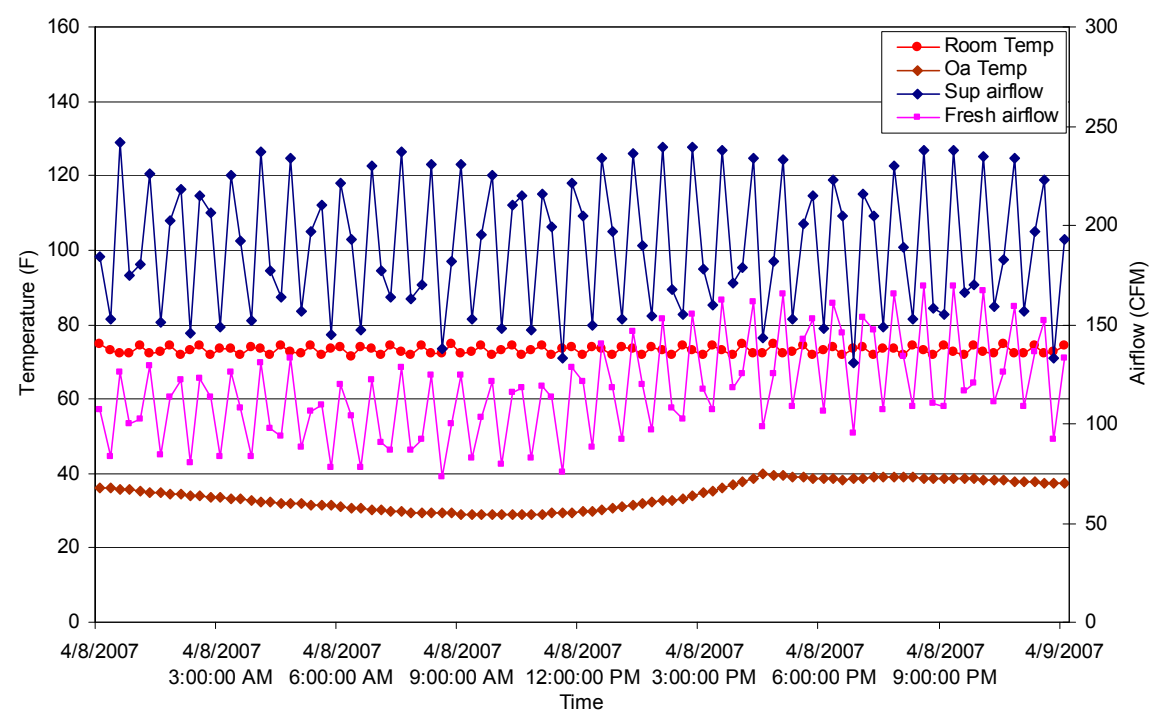

Figure 16. Air flow trending data for conventional control. 


\subsection{Improved Terminal Box Control}

With the new terminal box control sequence, the EMCS can automatically check the operation cycle based on the previous optimal control algorithm such as the seasonal operation cycles, normal cycle or weekend cycle and daily occupied time operation cycle. The outside fresh air intake ratio for the minimum ventilation mode can be calculated by Equations (17) and (18) from the AHU control input. To maintain room air temperature, the variable air flow and discharge temperature set point can be calculated by the previous control loop. Finally, the damper and valve modulate to maintain the room air temperature set point.

\subsubsection{Stability of Room Air Temperature Control}

An analysis of the stability of the room air temperature control in an actual system shows that the range of room air temperature is $70.9^{\circ} \mathrm{F}-73.6^{\circ} \mathrm{F}$, discharge air temperature is $55.6^{\circ} \mathrm{F}-86.9^{\circ} \mathrm{F}$ and supply air flow is 25.6-75.9 CFM during occupied time as shown in Figures 17 and 18. The room air temperature is able to maintain the set point $\left(73^{\circ} \mathrm{F}\right)$ within control deviation. The average room air temperature is lower than its set point. During the occupied period, the AHU's outside air intake is at minimum condition and the supply air flow set point is higher than the economizer season air flow set point to maintain the fresh air requirement as shown in Figure 18. During the unoccupied period, the lowest room air temperature is $68.7^{\circ} \mathrm{F}$; however, the system is maintained in a disabled condition because the room air temperature cannot reach the unoccupied operation heating set point $(\operatorname{Tr}<\operatorname{Tset}-4 \mathrm{~d})$. If the outside air condition is extremely cold or hot during the winter or summer season, the system will respond quickly based on the room air conditions. During the start time, the system tries to catch the room air temperature set point before occupancy. Therefore, it is assumed that there is proper and stable room air temperature control.

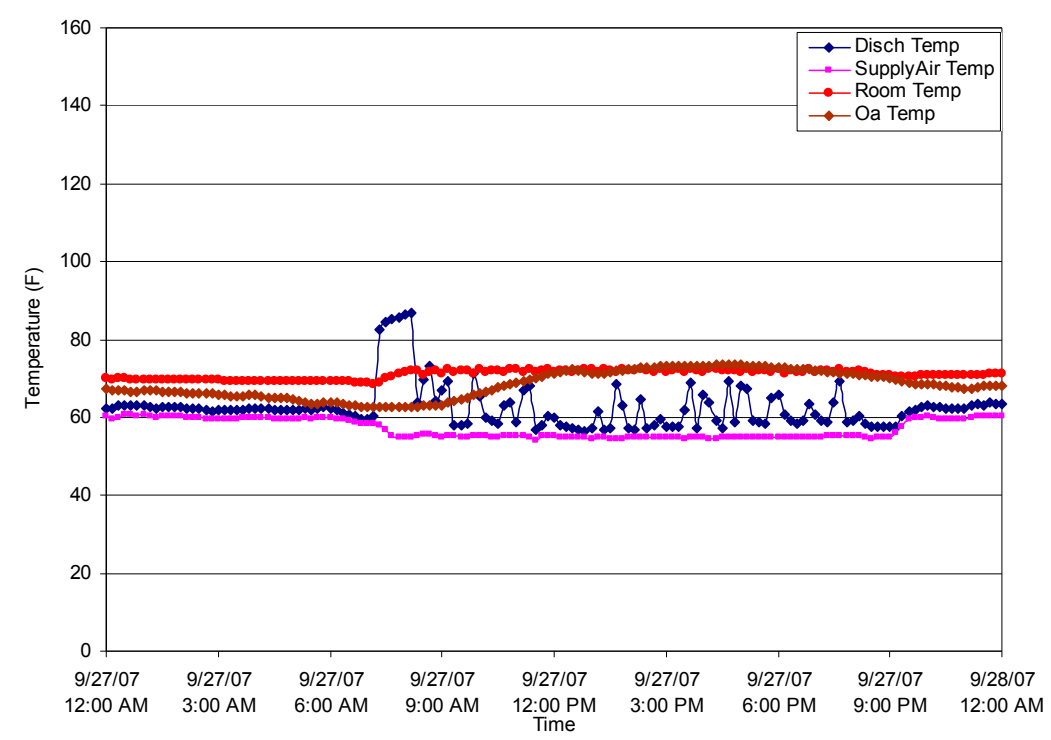

Figure 17. Temperature trending data of improved control.

\subsubsection{Thermal Comfort}

If the minimum air flow is less than required, there may be thermal comfort issues such as indoor air quality problem and lack of air circulation. Measurement of $\mathrm{CO}_{2}$ in occupied spaces has been widely used to evaluate the amount of outdoor air supplied to indoor spaces. To verify indoor air quality due to reductions in minimum air flow, measurements were performed on the $\mathrm{CO}_{2}$ levels using indoor air quality meters. The average $\mathrm{CO}_{2}$ level was in the range of $350-450 \mathrm{ppm}$. The average outdoor air concentration was $300 \mathrm{ppm}$. According to ASHRAE Standard 62, comfort criteria are 
likely to be satisfied if the ventilation results in indoor $\mathrm{CO}_{2}$ concentrations less than $700 \mathrm{ppm}$ above the outdoor air concentration, which is representative of delivery rates of outside air. Therefore, it is assumed that any IAQ problems due to reduction of the minimum air flow set point will not happen.

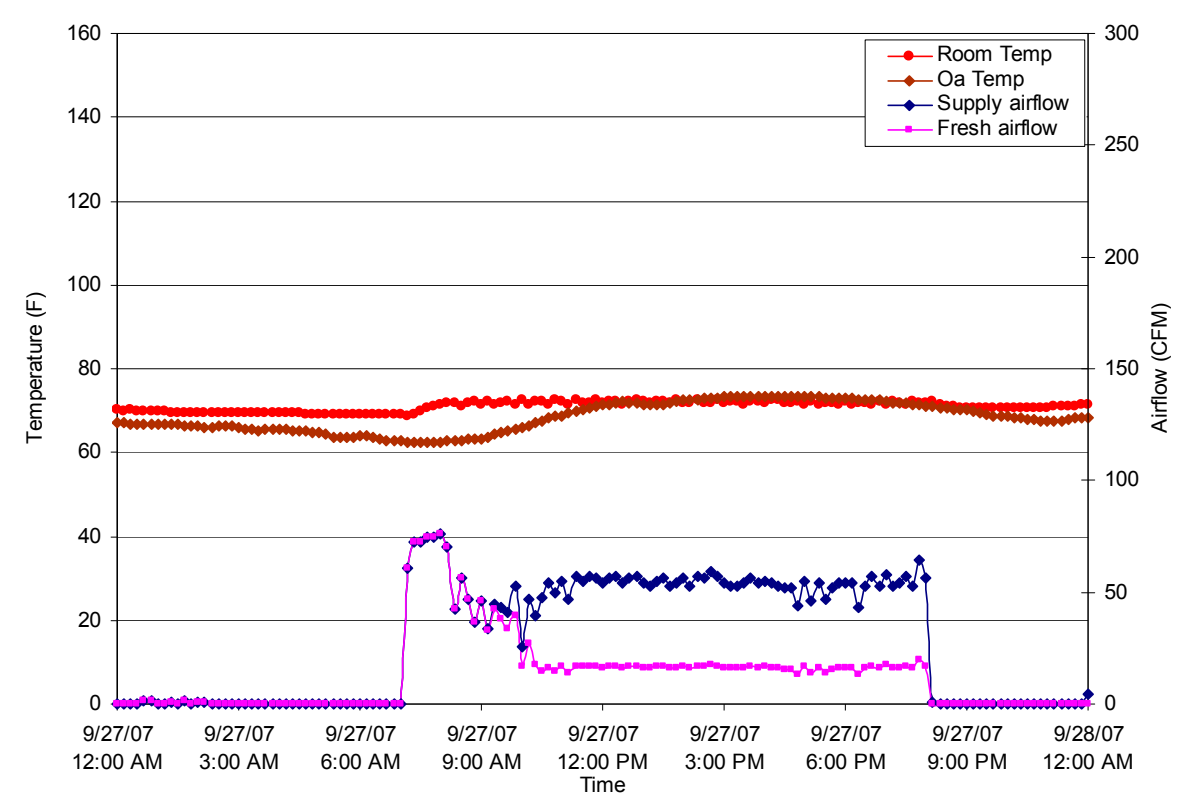

Figure 18. Air flow trending data of improved control.

\subsubsection{Potential Energy Savings}

The reheat energy savings can be considered as the reheat energy consumption required to heat the reduced air flow from the supply air temperature to the room temperature. The reheating coil energy consumption can be estimated based on Equation (22).

The cooling energy savings equals the cooling energy consumption to cool the reduced air flow from the room conditions to the supply air condition. When the room moisture production is neglected, the potential cooling energy consumption equals the potential reheat energy consumption. The cooling energy consumption can be estimated based on Equation (23) when the outside air temperature is higher than the supply air temperature. When the outside air temperature is lower than the supply air temperature, mechanical cooling can be eliminated by using an economizer. Therefore, the potential cooling energy savings is zero when an economizer is used. If an economizer is not used, the reduced air flow can decrease the cooling energy consumption even when the outside air temperature is lower than the supply air temperature.

When the impact of the fan efficiency decrease is neglected, the potential fan power savings can be estimated based on Equation (24). When the supply fan air flow is reduced, the supply fan speed should be reduced and the total fan power will be dropped. Therefore, significant fan power should be saved. With proper static pressure control from the air handling unit, the rooms receive adequate cooling air flow and do not overwhelm the fan.

$$
\begin{gathered}
\Delta E_{r h}=\dot{m} \cdot C_{p} \cdot\left(\alpha_{\min }{ }^{\prime}-\alpha_{\min }\right) \cdot\left(T_{r}-T_{s}\right) \\
\Delta E_{c}=\dot{m} \cdot C_{p} \cdot\left(\alpha_{\min }{ }^{\prime}-\alpha_{\min }\right)\left(h_{r}-h_{s}\right) \\
\Delta E_{f}=\dot{m} \cdot P_{s, d} \cdot\left(1-\alpha_{s}{ }^{2} P_{s, d}\right) / \eta_{f, d}
\end{gathered}
$$

In order to evaluate the thermal energy consumption in the actual system, reheating energy consumption can be calculated with Equation (4). The energy consumption is 119,721 Btu/hr day when there is a conventional control sequence. On the other hand, the energy consumption is $6758 \mathrm{Btu} / \mathrm{hr}$ 
with an improved control sequence. The thermal energy consumption with improved minimum air flow is less than that with conventional minimum air flow. Based on the trending data, the reheating energy cannot be compared between conventional and improved control sequences because the outside air conditions are not the same. However, reduction of supply air flow and discharge air temperature should save fan power, cooling and heating energy consumption by optimal terminal box control algorithms.

\section{Conclusions}

In this study, applicable optimal terminal box control algorithms for EMCS are suggested. To improve the conventional terminal box control sequence, dynamic models were analyzed, optimal control algorithms were developed, and the developed EMCS algorithms were then applied to an actual building. The terminal box energy consumption and thermal performance were compared between conventional and improved control. The results are as follows.

(1) In conventional control, the room temperature could not maintain its set point because the minimum air flow supplies an inadequate air flow for a conditioned space without considering building operation conditions. The minimum air flow is higher than required, which often leads to significant simultaneous heating and cooling, in addition to excessive fan power.

(2) Improved control can stably maintain the set room air temperature and reduce energy consumption, compared to conventional control. Measurements of $\mathrm{CO}_{2}$ levels show there is no indoor air quality problem when the minimum air flow set point is reduced.

(3) In energy measured results, the thermal energy consumption with improved control is less than that with the conventional control. Therefore, if developed EMCS control algorithms are applied, a terminal box can reduce thermal energy.

Acknowledgments: This research was supported by a grant (16AUDP-B079104-03) from Architecture \& Urban Development Research Program funded by Ministry of Land, Infrastructure and Transport of Korean government.

Author Contributions: All authors contributed to this work. Yoon-Bok Seong performed the result analysis and wrote the major part of this article. Young-Hum Cho was responsible for this article and gave conceptual advice.

Conflicts of Interest: The authors declare no conflict of interest.

\section{Nomenclature}

$T_{r}$

$T_{\text {out }}$

$T_{a d, j}$

$q_{i}$

$\dot{m}_{v}$

$\rho$

V

$C_{a}$

$U_{i}$

$U_{j}$

$A_{i}$

$A_{j}$

$T_{S}$

$T_{d, s}$

$T_{s, w}$

$T_{r, w}$

$\dot{m}_{a}$

$\dot{m_{w}}$
Room air temperature, ${ }^{\circ} \mathrm{F}$

outside air temperature, ${ }^{\circ} \mathrm{F}$

interior air temperature, ${ }^{\circ} \mathrm{F}$

internal heat gains, Btu/hr

mass flow rate of ventilation air, $\mathrm{lbm} / \mathrm{h}$

standard air density, $\mathrm{lbm} / \mathrm{ft}^{3}$

volume of room air mass, $\mathrm{ft}^{3}$

specific heat of air, Btu $/ \mathrm{lbm}^{\circ} \mathrm{F}$

heat transfer coefficient of exterior wall, Btu/lbm $\mathrm{ft}^{2}{ }^{\circ} \mathrm{F}$

heat transfer coefficient of interior wall, Btu/lbm ft ${ }^{2} \mathrm{~F}$

area of exterior wall, $\mathrm{ft}^{2}$

area of interior wall, $\mathrm{ft}^{2}$

steady state supply air temperature, ${ }^{\circ} \mathrm{F}$

steady state discharge air temperature, ${ }^{\circ} \mathrm{F}$

steady state supply water temperature, ${ }^{\circ} \mathrm{F}$

steady state return water temperature, ${ }^{\circ} \mathrm{F}$

mass flow rate of air, $\mathrm{lbm} / \mathrm{h}$

mass flow rate of water, $\mathrm{lbm} / \mathrm{h}$ 


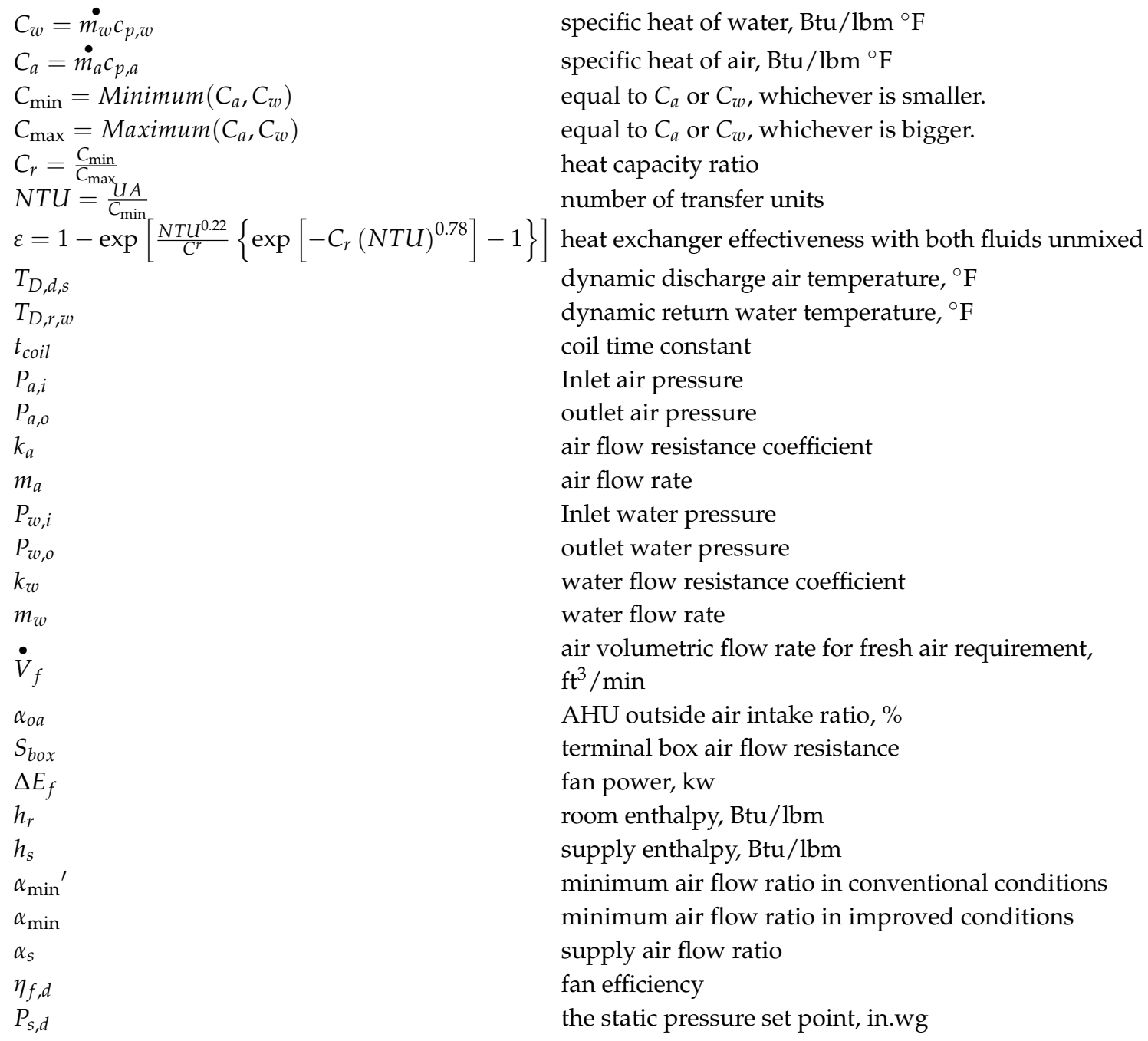

\section{References}

1. Elovitz, D.M. Minimum outside air control method for VAV systems. ASHRAE Trans. 1995, 101, $613-618$.

2. Krakow, K.I. Economizer control. ASHRAE Trans. 2000, 106, 13-25.

3. Ke, Y.P. Optimized supply air temperature (SAT) in variable-air-volume (VAV) systems. Energy Int. J. 1997, 22, 601-614. [CrossRef]

4. Zaheer-uddin, M. VAV system model to simulate energy management control functions: Off-normal operation and duty-cycling. Energy Convers. Manag. 1994, 35, 917-932. [CrossRef]

5. Engdahl, F.; Johansson, D. Optimal supply air temperature with respect to energy use in a variable air volume system. Energy Build. 2004, 36, 205-218. [CrossRef]

6. Wei, G.; Claridge, D.E.; Liu, M. Optimize the Supply Air Temperature Reset Schedule for a Single Duct VAV system. In Proceedings of the Twelfth Symposium on Improving Building Systems in Hot and Humid Climates, San Antonio, TX, USA, 15-17 May 2000; pp. 154-157.

7. Nassif, N.; Moujaes, S. A new operating strategy for economizer dampers of VAV system. Energy Build. 2008, 40, 289-299. [CrossRef]

8. Taylor, S.T.; Stein, J. Sizing VAV Boxes. ASHRAE J. 2004, 46, 30-35.

9. Cho, Y.; Liu, M. Minimum air flow reset of single duct VAV terminal boxes. Build. Environ. 2009, 44, 1876-1885. [CrossRef]

10. Cho, Y.; Liu, M. Correlation between minimum air flow and discharge air temperature. Build. Environ. 2010, 45, 1601-1611. [CrossRef]

11. Kang, S.; Kim, H.; Cho, Y. A Study on the control method of single duct VAV terminal unit through the determination of proper minimum air flow. Energy Build. 2014, 69, 464-472. [CrossRef] 
12. Kim, H.; Kang, S.; Cho, Y. A study on the control method without stratification of single duct VAV terminal units. J. Asian Arch. Build. Eng. 2015, 14, 467-474. [CrossRef]

13. Taylor, S.; Stein, J.; Paliago, G.; Cheng, H. Dual maximum VAV box control logic. ASHRAE J. 2012, 54, 16-24.

14. Zhang, B.; Li, Y.; Lau, J.; Liu, M. Demand control ventilation: Influence of terminal box minimum air flow setting on system energy use. Energy Build. 2014, 79, 173-183. [CrossRef]

15. American Society of Heating, Refrigerating and Air-Conditioning Engineers (ASHRAE). Ventilation for Acceptable Indoor Air Quality (IAQ); ASHRAE Standard 62.1-2004; ASHRAE: Atlanta, GA, USA, 2004.

(C) 2016 by the authors; licensee MDPI, Basel, Switzerland. This article is an open access article distributed under the terms and conditions of the Creative Commons Attribution (CC-BY) license (http:/ / creativecommons.org/licenses/by/4.0/). 